\title{
How Media Influence the Intergroup Relationships Between LGBT and the Non- LGBT Community in China
}

\author{
Yize Tan
}

\author{
${ }^{1}$ Nanjing Foreign Language School \\ *Corresponding author. Email: 2199873572@qq.com
}

\begin{abstract}
The life of the LGBT community is filled with challenges, which might have negative influences on their mental and physical well-being. While certain countries are improving equal rights for the LGBT community through legislation, others are lagging. For example, the Chinese LGBT community fights for their rights but often failed. Drawn upon empirical evidence, diverse representations of the LGBT community on media can increase public understanding and enhance inclusive attitudes towards this group. Thus, this project aims to examine how these benefits generated from media representations can be applied to the intergroup relationships between LGBT and non-LGBT communities in China.

By reviewing current literature, this project summarized empirical findings of intergroup relationships and media representations in China and found a prevalent amount of stereotypical and discriminatory depictions of the LGBT community among television, films, as well as news reports. Drawn upon the social identity theory, such depictions of the LGBT community, as a social minority group, has detrimental effects on intergroup relationships, including dampening the positive distinctiveness of the LGBT community, disseminating prejudice and harmful messages, and exacerbating intergroup relations between LGBT and non-LGBT individuals.

Following the review summarized in this paper, this project suggests that Chinese media should have used its platform to promote inclusive and diverse representations of the LGBT community. Such acts will have long-enduring effects on improving intergroup relationships. Moreover, the advent of communication technologies provides an alternative means for the LGBT community to gain positive distinctiveness. Social media provide a relatively free and vibrant space for the LGBT community to act collectively but also use social creativity to express themselves in a positively distinct fashion.
\end{abstract}

Keywords: media, LGBT, intergroup relationships, social identity theory

\section{INTRODUCTION}

My research question is how media influence the intergroup relationships between LGBT and the nonLGBT community in China. This question is worth looking into as follows.

LGBT is the abbreviation of LGBTPQAA, which includes lesbian, gay, bisexual, transexual, pansexual, queer, asexual, and ally. According to some census, approximately $4.5 \%$ of US adults identified as LGBT in 2017 (Gallup et al, 2017)[1], about 14.65 million people.

However, the life of the LGBT community is filled with challenges. Studies in the US show that, compared with non- LGBT social groups, LGBT people have worsened cardiovascular diseases, and gay men and lesbians are more likely to have migraines (Ganson et al., 2020). Psychosocial well-being is often associated with LGBT individuals' physical health. The poor health condition of the LGBT population may be because of the pressure caused by prejudice and social stereotypes. These include personal pressure (such as internalized homo-negativity, fear of rejection, and deliberately concealing sexual orientation) and interpersonal pressure (such as stigmatization, prejudice, and discriminatory acts). Therefore, LGBT people have higher rates of anxiety, depression, and even suicidal tendency (Giacomo et al, 2018; Marshall et al, 2013)[2] 
Fortunately, social acceptance towards LGBT in western society has been increasing. For example, a study found that the acceptance of the LGBT community among American adults has increased to $73 \%$ by 2020 from that of $43 \%$ in 1977 (Gallup, 2015)[3]. As for samesex marriage, since the Netherlands became the first country to recognize same-sex partner marriage in 2001, 29 countries have approved same-sex marriage (Business Insider, 2020). At the same time, the average age of "coming out" of the LGBT community has declined to 14 years old. It can be seen that social acceptance makes teenagers more willing to acknowledge and reveal their sexual and gender identity. These inclusive social policies of the LGBT group demonstrated the increased social acceptance towards this community.

The increased social acceptance is partially due to the diverse media representations within their media landscape. As media reach a large size of audience and have important representative significance, it can have great effects. Western media landscape helps to improve the conditions of LGBT. Taking some Western media research and representations as examples, "Stigma" is a concept put forward by American sociologist Goffman (1963)[4]. Stigma is an illuminating excursion into the situation of people who are unable to conform to standards that society calls normal (Goffman, 1963). Stigmatized people are those who do not have full social acceptance and are constantly striving to adjust their social identities (Goffman, 1963). Moreover, a study used the parasocial contact theory to help increase the number of people that have positive attitudes towards LGBT. (Schiappa et al, 2005)[5] It chose 174 US undergrads and randomly assigned them to pre-test or not. They watched 10 episodes of 6 Feet Under about the romance of Keith and David. Then the research did the post-test measure for all characters, it is found that there is uncertainty reduction, social attraction, physical attraction, task attraction, and the viewers' perceived homophily. There are more positive attitudes toward the gay men and lesbian groups in the post-test measure than the pre-test measure.

While the social acceptance towards LGBT has increased in democratic systems, LGBT communities are large and constantly being marginalized and oppressed in other regimes. Consider the socio-cultural context of the LGBT community in China here. While most progressive Western societies get to know more about the LGBT community and have a generally more positive attitude towards them, the Chinese public does not understand enough information and knowledge about LGBT members (Pan, 2017). In contrast to many policies that exist in western countries, the Chinese government had no active support for this community for a long time. There are no anti-discrimination laws in place, same-sex marriage remains illegal, and there is no recognition of same-sex couples. (Queer in the world)[6]
In China, the LGBT community has a population of about 70 million. According to the report of the United Nations (2016), only $5 \%$ of LGBT groups in China have disclosed their LGBT identity in their work units or schools, and only $17 \%$ of LGBT groups have disclosed their LGBT identity to their families[7]. In China, the living circumstance of LGBT has always been much more difficult. Chinese LGBT groups are trying to change this situation through a series of legal cases, but so far, almost all similar cases have ended in failure.

In 2015, a student from Sun Yat-Sen University found that textbooks had discriminatory descriptions of homosexuality (Ning, 2016)[8]. Some textbooks for psychology and pathology still regard homosexuality as a disease and abnormality, and more than $50 \%$ of the Chinese textbooks believe that homosexuality needs "conversion therapy". Accordingly, in March 2015, the students reported to the General Administration of press and publication and the Department of Education that the textbook had stigmatized homosexual groups. but the court rejected this case. On May 14, 2015, the student applied to the Ministry of Education to ensure its supervision on teaching materials and the punishment for incorrect use of teaching materials. The Ministry of Education has not responded. After that, the student filed a lawsuit with the first intermediate people's Court of Beijing. On August 14, the lawsuit was accepted to be put on file for trial. This case was widely concerned by the national media. However, it at last ended in Qiu's failure.

On July 6, 2021, We Chat (a large Chinese social media platform) banned LGBT-related official accounts of some Chinese major universities. Including but not limited to Tsinghua University's purple, Peking University's colorsworld, Nanjing University's one sky, Fu Dan University's Zhihe society, etc. There even are many people on the Internet who support closing all these clubs about LGBT.

These cases can be seen as evidence that the Chinese public's knowledge and acceptance of the LGBT group are still limited. Therefore, it can set off the importance that China needs to alter its prejudice against the LGBT community. Especially when we look at the context of China, any problem will become more significant because of China's large population. There is still a long way to go for China's LGBT group to achieve equal rights and eliminate prejudice. We can learn from western society; we have found that media has played an important role in improving social acceptance towards LGBT in western society at the beginning of the paper. Undoubtedly, Media has a wide field and aims at varieties of audiences, itself can help people contact with those they'd normally avoid or have little opportunity to encounter. Therefore, focusing on our context of China, my research question is how media can influence the inter-group relationship between LGBT and the non- 
LGBT community in China. This question is worth looking into.

\section{MEDIA REPRESENTATION OF THE CHINESE LGBT COMMUNITY}

I will focus on mass media representations of LGBT here, summarize the literature and categorize them based on different medium

\subsection{LGBT representations in $T V$ and movies}

This section mainly analyzes and summarizes the characterization of LGBT characters in Chinese film and television works and reflects on the upsurge of LGBT film and TV works based on past research.

It's difficult to create and publish LGBT-related works, especially in the environment of Chinese films. However, since the 1990s, under the influence of Western media works, queer theory has entered the public's field of vision, LGBT films are becoming famous internationally, and relevant Chinese films have begun to develop (Jin, 2020)[9], for example, the Farewell to My Concubine. The renewal of the media environment, the development of the network, and the varieties of audiences provide a space for the survival and growth of LGBT films to a certain extent. (Jin, 2020). However, after further analysis of China's LGBT online TV and films, it is found that although the development is fast, the whole market is chaotic and many problems exist (Zuo, 2017)[10]. There are some common features of LGBT representations on Chinese media today, and they are stereotyped.

First, there are biases in characterization, some are incorrect or immoral, There are four main character types in LGBT film and television works that we can summarize (Ding, 2020)[11].

The first type of queer image strongly resists the conflicts between their own natural physiological desires and social mainstream values. These characters resist the conflict using aggressive actions and exaggerated modeling. The advantage is that this is the most attractive image to the public in queer's film and television works; however, the problem is that this way of resisting external conflicts is highly stereotypical. At first, the gay image appeared as a clown in comedy to meet the audience's curiosity about this minority group and create a different film viewing experience (Jin, 2020)[9]. However, the use of LGBT roles to enhance the novelty of the film is a lack of a serious and respectful attitude towards this minority group. The character settings of gay men in comedy films are usually feminine while the lesbian characters are masculine, shown by their strong physique, short hairstyle, and male clothing. These stereotypical representations that are taken out of context and even distort the real image of queer groups undoubtedly have negative effects which I will explain in more detail in the following sections. Transvestite is a special gender symbol in gay films. It shows the resistance of gay men and women towards the traditional gender division of the mainstream society. The transvestite gives the audience a very direct visual impact and helps to bring a more dramatic film plot, which can meet the audience's curiosity. However, for those audiences who seldom or never have contact with the LGBT people in reality, these transvestite will lead them to build LGBT images in this exaggerated and stereotypical way shown in the film they watch. This will cause further prejudice, alienation, and labeling of LGBT.

The second type of character is LGBT people who suppress conflict. They don't want to confess their LGBT identities, they try to fit in the mainstream and hide their real identity. In many Queer Film and TV works, we can see most of this type which basically corresponds to reality. The advantage of this image type is to stimulate the audience's empathy towards this minority group. But the problem is that there is undeniable deception in such image formation, as these characters lie to their partners or friends. Film and TV works cannot spread deception like this to encourage the LGBT to cheat on others about their own natural sexual identity, otherwise, it will cause serious moral misleading and worsen the stigmatization of the queer group.

The third image type is LGBT that accepts the conflict and faces it calmly in a normal way. These characters who are willing to face and admit their sexual identity convey positive values to the public.

The fourth is the non- LGBT characters. Most of them shown on the screen are oppressors who are hostile to LGBT and have an easier life, this is also unfavorable to LGBT and non- LGBT community's inter-group relationship.

Except for the characterization, there are still some problems in LGBT film and television works, the content of LGBT media works is rough and over-commercialized, the theme is shallow and not diverse, the narrative content does not change a lot and the supervision of relevant laws and regulations on such media works is not advanced, etc (Zuo, 2017)[10]. Due to the censorship and considering the acceptance of the audience, there are still few LGBT elements in China's cinema films. Movies with LGBT elements will avoid LGBT terms, marginalizing the weight of LGBT plots in the overall plot (Zuo, 2017).

\subsection{LGBT representations in news}

China News Network is an authoritative and guiding online media which can reflect the attitude of the mainstream media to LGBT groups to some extent. After studying the theme reports on gay men and women on China News Network in recent ten years, it is found that 
there are also many problems. Unbalanced reporting topics, single reporting content, and biased image construction are the problems of gay reporting on China news networks (Ji, 2018)[12].

How would such stereotyped and problematic LGBT media representations influence today's inter-group relationships between LGBT and the non- LGBT community in China? Why do we need to care about these problems and why do they have negative effects? The social identity theory provides a useful framework here.

\section{SOCIAL IDENTITY THEORY}

Social identity theory (SIT) was first introduced by Tajfel (1978) and Turner (1979)[13]. There are basically two major parts of SIT, the first is the psychological part which relates to the following section 4 , and the second part is the socio-structural part which I will address in section 5. The psychological part includes several psychological processes, and it is built on several key propositions, including self-categorization and social comparison.

Their first proposition is that people have the innate tendency to categorize themselves and others into certain social groups. This is called social categorization or selfcategorization. Social groups (e.g., social class, family, race/ethnicity, etc.), which people consider themselves belong to, are an important source of self-esteem. Groups give people a sense of social identity, the world then is divided into "them"(outgroup) and "us"(ingroup) through this process of social categorization. Second, some in-groups are salient in each context. The psychological salience must exist for the following processes to be carried out. In the third process, the social comparison takes place. This means that people will evaluate their own ingroup salience relative to their relevant outgroups. When people aim to evaluate their ingroup but lack general terms or standards to compare with, they compare with outgroups (Festinger, 1954)[13]. Another key proposition is about positive distinctiveness, positive distinctiveness describes the result of social comparison. If the ingroup is evaluated more positively than the outgroup after social comparison, people of the ingroup perceive positive distinctiveness. Social identity is defined as the combination of self-categorization and social comparison, and it influences an individual's selfesteem.

\section{SIT AND ITS APPLICATION TO MEDIA REPRESENTATION OF THE CHINESE LGBT COMMUNITY}

Media disseminate a significant amount of information. According to SIT, media deliver metamessages about the relative position of ingroup and outgroup. Based on media information, people tend to self-categorize themselves into certain groups attached with positive distinctiveness. Hence, different social groups use media to gain positive group status and increase self-esteem (Trepte et al, 2016). A social group can be portrayed as positive, negative, or neutral. Exposure to such media depictions provides individuals understanding of their group status, influencing their selfesteem. If social comparison taking place while watching media lead to strong positive distinctiveness of one's social group, an individual's self-esteem would be increased. From a societal perspective, media representation, especially those stigmatizing social minority groups, could have long-lasting effects, such as worsening intergroup conflict and discrimination and possibly enduring suppression upon certain social groups. Based on SIT and some features of Chinese LGBT media representations summarized above, current media representations about the Chinese LGBT community are problematic. When it comes to this information that is provided on the media, according to SIT, stereotypical representations of the LGBT community might lead to the internalization of negative perceptions of one's own social identities but also continue to marginalize this community. Additionally, these representations have been perpetrating group differences, possibly leading to detrimental effects towards intergroup relationships between LGBT and non-LGBT communities. The following illustrates, in greater detail, how the theoretical assumptions of SIT can be applied to the Chinese LGBT community in relation to media representations.

On the one hand, towards the LGBT community as a social group, they might perceive themselves as representations on the screen. While engaging in social comparison, media provide critical references in terms of group vitality and group status. Nevertheless, LGBT individuals strive to obtain positive distinctiveness and increase self-esteem. However, according to previous analysis of Chinese media representations, the main themes of Chinese LGBT members are biased, shallow, and homogeneous, and their characters portrayed act as a clown to increase the public's curiosity or act as a tragic role to enhance audiences' empathy. Thus, it is challenging to observe the positive and objective depiction of their ingroups, which might hinder their ability to generate a positive evaluation of their ingroup status. As a result, they lack chances to obtain positive distinctiveness over media when it comes to the social comparison.

In terms of their own social identity formation and self-esteem, unfortunately, current Chinese media representations can still cause further harm to the LGBT community. For example, some of the LGBT characters have aggressive actions or wear exaggerated clothing, some of the gay men characters are feminine while lesbian characters are masculine. These identities shown on the screen are different from what the LGBT consider themselves to be. Stereotypical representation harmed 
their self-esteem. Media representation reflects group vitality. That is negative representation can be often associated with low group status. The Chinese LGBT community might associate themselves with low group status and exert a negative influence on their well-being. They may hide their identity to deceit others or resent the non- LGBT community after exposure to such depictions. Furthermore, there is a laboratory experiment that examined selective exposure more directly by tracking the selection of, and time spent with, news articles varying in valence (positive vs. negative) and news character skin color (Black vs. White) (Appiah et al, 2013)[13]. We can apply it to the LGBT situation. Among LGBT members, there may be ingroup favoritism, which means the LGBT members may spend more time on positive news featuring LGBT than on positive and negative news featuring non- LGBT community; moreover, outgroup derogation may occur, which means LGBT group spend more time on negative than positive news featuring non-LGBT. This selective exposure might have arisen because they perceive their own ingroup as stigmatized and of lower status as well as identifying more strongly with their ingroup. This will harm their contacts and relationships with the outgroup.

On the other hand, for non- LGBT individuals, such stereotypical and negative depictions of their outgroup could strengthen their own positive distinctiveness, but also further marginalize and oppress the social minority group, namely the Chinese LGBT community in this case. As summarized above, non- LGBT characters shown on the screen are often oppressors and are hostile to LGBT individuals, they have an easier life without the conflict between themselves and the mainstream group. Intergroup discrimination can emerge due to salient differences across social groups depicted on media. Then, the non- LGBT may keep looking at the biased media representation and embed this kind of stereotypical LGBT image in their heart, there will be more discrimination. Media representations threaten groups with low status, for instance, highlight prejudice among marginalized groups. Biased media representation reinforced public misunderstanding towards the LGBT group and impeded positive intergroup contact.

\section{WHAT IS NEXT?}

As I mentioned in section 3, the second part of SIT is the socio-structural part. According to SIT, if a positive evaluation of one's ingroup is not possible, outgroups could employ some other strategies or agencies to promote social changes. I will briefly summarize several strategies here. First of all, it is individual mobility. If individuals cannot gain positive distinctiveness of their ingroups, they may leave their current group and join another group with a higher social status. This will automatically elevate the group status of the individual. The second strategy is social creativity. Ingroup members can enhance positive distinctiveness by adjusting elements of the social comparison, including choosing a different dimension to compare with, adjusting value judgments so that what was considered negative before is now considered positive, or comparing the ingroup to a different outgroup. The third one is collective action. Ingroup members can work together to improve their situation. In this case, the marginalized group members will directly compete with the social majority group to reverse the imbalanced group status (Tajfel, et al, 1979)[13].

Some of the strategies here can be applied to the LGBT community. The LGBT members can seek alternative paths to gain positive distinctiveness for themselves; however, since sexual orientation is not a choice; it is what you're born with (Amir, 2019)[14], so it means that the boundary for LGBT to join in the nonLGBT group is not permeable; thus, the individual mobility strategy cannot be used. They instead, could use social creativity to seek positive distinctiveness and higher self-esteem.

Nowadays, the advent of communication technologies provides such means. Social media come as a safe space by providing an agency for the Chinese LGBT members to employ social creativity and work collectively. For instance, in China, there are videos on Bilibili for LGBT members to express their own gender and/or sexual identities, which might be censored within the mainstream media. Members of the LGBT community could form tight-knit social circles on social media that celebrate shared identity traits. For instance, on these streaming services, LGBT members have the liberty to compare with non-LGBT groups on different dimensions. Such comparison might not be possible or often oppressed on mainstream media or in regular life. Moreover, Chinese LGBT members can attach new meaning towards negative or stereotypical traits defined by the non-LGBT community. Such re-definition is often achieved by displaying traditionally-perceived stereotypical traits of the LGBT community. LGBT members online take the chance to create a positive annotation for these traits and increase group vitality and positivity as a whole. For instance, these video bloggers online often cross-dress or use exaggerated mannerisms to combat the negative depictions on mainstream media, but also advocate for themselves and other fellow LGBT members. On social media, they also enjoy the freedom from conventional gender-specific roles in society, freedom to explore sexuality and relationships, and so on, enabling authenticity for these LGBT members (Whitman, 2008)[15]. For example, online streaming service has many intimate and personal stories about coming out, which could potentially help gay men and lesbians vicariously experience acceptance and empathy from the non-LGBT community members. Another example is the LGBT members could also express themselves as socially intelligent on social media 
(Vaughan \& Rodriguez, 2014)[16]. These positive strengths of the LGBT community may help them to gain positive distinctiveness in another way.

\section{CONCLUSION}

We realize that the LGBT life is challenging, especially in China, many problems do exist. Then after seeing the role of media in effectively helping western society to improve their attitude towards the LGBT community, we are inspired to analyze how media can influence the intergroup relationships between LGBT and the non- LGBT community in Chinese context. I summarize some features of the Chinese mass media representations of LGBT and categorize them based on different medium. It is found that they are problematic. According to the social identity theory, we can explain why these stereotypical and discriminating media works will generate negative effects on intergroup relationships; fortunately, SIT also provides alternative strategies like social creativity for the LGBT group to gain positive distinctiveness through media, specifically, the social media, and to increase ingroup social status and improve the intergroup relationships.

Based on SIT, the possible negative outcomes, and the possible helpful strategies, I would like to propose several suggestions to help the minority and help improve future intergroup relationships between the LGBT and non- LGBT communities. The characterization of LGBT members in media representations should be more serious and less stereotypical. The LGBT news report theme and the theme about LGBT media works should be more diverse and less commercialized. It should weaken the difference between the LGBT group and the nonLGBT community. It is better to focus more on the positive aspects of gay men and lesbian lives instead of paying all attention to the negative life experiences of these people. Except for the mass media, social media could develop further to help LGBT members gain higher self-esteem and reduce the discrimination of non-LGBT towards LGBT people. These summaries, analysis and suggestions, hopefully, can pave the path for future research on this topic, which is a field definitely worth digging for.

\section{REFERENCES}

[1] Newport, F. (2021, August 13). In U.S., estimate of LGBT population rises to $4.5 \%$. Gallup.com. Retrieved October 27, 2021, from https://news.gallup.com/poll/234863/estimate-lgbtpopulation-rises.aspx.

[2] LGBTQ+ students face 'sizable' mental health disparities. (n.d.). Retrieved October 27, 2021, from https://www.insidehighered.com/news/2021/10/26/ lgbtq-students-face-sizable-mental-healthdisparities.
[3] Gallup. (2021, September 22). LGBT rights. Gallup.com. Retrieved October 27, 2021, from https://news.gallup.com/poll/1651/gaylesbianrights.aspx.

[4] Goffman, E. (1986). Stigma: Notes on the management of spoiled identity. Touchstone

[5] The parasocial contact hypothesis - MIT comparative media ... (n.d.). Retrieved October 27, 2021, from https://cmsw.mit.edu/wp/wpcontent/uploads/2014/05/The-Parasocial-ContactHypothesis.pdf.

[6] China, C. (2021, August 3). LGBT rights in China: What travellers should know before going! . Queer In The World. Retrieved October 27, 2021, from https://queerintheworld.com/lgbt-rights-in-china/.

[7] Daokebaba. (n.d.). Survival status of sexual minorities in China - a survey report on social attitudes based on sexual orientation, gender identity and gender expression. Daokebaba. Retrieved October 27, 2021, from https://www.doc88.com/p5148682208837.html.

[8] She lost her third lawsuit against the Ministry of education. When can homosexuality be corrected in textbooks Mustard heap. (2016, October 13). Retrieved October 28, 2021, from https://www.jiemodui.com/N/62449.

[9] Jin, H. (n.d.). A Study on Homosexual Images in Chinese Films.

[10] Zuo, Y. (n.d.). The research for Communication Characteristics and The development strategies of BL internet drama.

[11] Ding, Y. (n.d.). Struggle between Sin and Desire: Conflict Construction between Queer and Christianity in European and American Film and Television Works .

[12] Research on gay theme reporting of China News Network in recent ten years. Research on gay theme reporting of China News Network in recent ten years - China HowNet. (n.d.). Retrieved October 28, 2021, from https://kns.cnki.net/kcms/detail/detail.aspx?dbcode =CMFD\&amp; dbname=CMFD201901\&amp;filen ame $=1018717546 . n h \& a m p ; v=f z h F F 8 L h o b o k 55 M J$ bS2WwwQmUnAdDed5qmfYXBiz8ZtnXcZ6OV UR1pt3t8\%25mmd2B2JUqB.

[13] Trepte, S., \& Loy, L. S. (2017). Social Identity Theory and self-categorization theory. The International Encyclopedia of Media Effects, 1-13. https://doi.org/10.1002/9781118783764.wbieme00 88 
[14] Ings, A., \& Ings, A. U. T. H. O. R. A. (2020, January 14). Sexual orientation isn't a choice; it's what you're born with. Loquitur. Retrieved October 28 , 2021, from https://www.theloquitur.com/sexual-orientationisnt-a-choice-its-what-your-born-with/.

[15] Whitman, J. (2018, March 24). The positive aspects of being a lesbian or gay man. Professional Psychology: Research and Practice. Retrieved October 28, 2021, from https://www.academia.edu/1309200/The_positive_ aspects_of_being_a_lesbian_or_gay_man.

[16] 6 unique strengths prevalent in the LGBT community, and how to use them. Lighthouse. (2019, January 9). Retrieved October 28, 2021, from https://blog.lighthouse.lgbt/research-6-strengthsunique-lgbtq-community/. 